Bangladesh Journal of Neuroscience 2018; Vol. 34 (1): 9-16

\title{
Association between Serum Thyroid Hormone Levels and Functional Outcome in Acute Ischemic Stroke Patients
}

\author{
RASHID MB ${ }^{1}$, DEY SK ${ }^{2}$, HANNAN MA ${ }^{3}$, ISLAM MR ${ }^{4}$, ISLAM MF ${ }^{5}$, \\ SARKER I ${ }^{6}$, UDDIN MN ${ }^{7}$, HASSAN $^{8}$
}

\begin{abstract}
Background and Objectives: Neuroendocrine profile is significantly altered in acute ischemic stroke. Objective of the study was to determine association between serum thyroid hormone levels and functional outcome in acute ischemic stroke patients. Method: It was a cross sectional analytical study which was conducted in the Department of Neurology, BSMMU, Dhaka. Total 60 acute ischemic stroke patients within 14 days of onset of symptoms confirmed by neuroimaging were selected purposively from department of Neurology, BSMMU. Blood sample was collected from the patient on admission, and was analyzed at the Department of Biochemistry, BSMMU for estimation of serum Thyroid hormones (FT3, FT4, TSH) level. Modified Rankin Scale (mRS) score was done after 1 month of stroke. Poor outcome was defined as $m R S>2$ and good outcome was defined as 0-2. Result: Among Sixty patients 39(65\%) had normal FT3 level and rest 21(35\%) had low FT3 level. The mean ( $\pm S D$ ) serum FT3 Level was 2.77 $( \pm 0.99) \mathrm{pmol} / \mathrm{L}$ in poor outcome group and $3.67( \pm 0.65) \mathrm{pmol} / \mathrm{L}$ in good outcome group which was statistically significant $(p=0.001)$. A negative correlation co-efficient $(r=-$ 0.380) was found between mRS score and serum FT3 concentration, which was also statistically significant $(p=0.001)$. On logistic regression analysis, low serum FT3 concentration remained independent predictor of poor outcome of acute ischemic stroke patients ( $p=0.001$, Odds Ratio $=3.567$ ). Conclusion: In patients with acute ischemic stroke lower serum FT3 level was significantly associated with poor functional outcome.
\end{abstract}

Key words: Acute ischemic stroke, Serum FT3, mRS score.

\section{Introduction:}

Stroke is one of the major global health problems. According to WHO Fact Sheet ${ }^{1}$ stroke is the second most common cause of death throughout the world and is the most common cause of severe adult physical disability. However according to GBD 2015 stroke is the number one cause of death in Bangladesh and is also common cause of physical disability. About one-fifth of patients with an acute stroke die within a month of the event and at least half of those who survive are left with physical disability ${ }^{2}$. The reported prevalence of stroke in Bangladesh is $0.3 \%{ }^{3}$. The high number of disabilityadjusted life-years lost due to stroke (485 per 10,000 people) show that stroke severely impacts
Bangladesh's economy ${ }^{3}$. Stroke can be classified into two major categories like ischemic and hemorrhagic. Ischemic strokes are those that are caused by interruption of the blood supply, while hemorrhagic strokes are the ones which result from rupture of a blood vessel. Most embolic strokes characteristically occur suddenly and the deficit reaches its peak almost at once. Thrombotic strokes may have an abrupt onset, but they evolve somewhat more slowly over a period of several minutes or hours and occasionally days; in the latter case, the stroke usually progresses in a saltatory fashion. In hypertensive cerebral hemorrhage, also abrupt in onset, the deficit may be virtually static or steadily progressive over a period of minutes or

1. Dr. Mohammad Bazlur Rashid, Final Part Student, MD (Neurology), Dept. of Neurology, BSMMU, Dhaka.

2. Dr. Subash Kanti Dey, Associate Professor, Dept. of Neurology, BSMMU, Dhaka.

3. Prof. (Dr.) MA Hannan, Professor, Dept. of Neurology, BSMMU, Dhaka.

4. Prof. (Dr.) Md. Rafiqul Islam, Professor \& Chairman, Dept. of Neurology, BSMMU, Dhaka.

5. Dr. Md. Fakrul Islam, EMO, Dept. of Neurology, Dhaka Medical College Hospital, Dhaka.

6. Dr. Imran Sarker, Registrar (Clinical Neurology), NINS\&H, Dhaka, Bangladesh.

7. Dr. Mohammad Nur Uddin, Final Part Student, MD (Neurology), Dept. of Neurology, BSMMU, Dhaka.

8. Dr. Shahadat Hassan, Final Part Student, MD (Neurology), Dept. of Neurology, BSMMU, Dhaka 
hours, while subarachnoid hemorrhage is almost instantaneous ${ }^{4,5}$. Pituitary thyroid axis is significantly altered in patients with acute stroke ${ }^{6}$. Low triiodothyronine (T3) level has been shown to be associated with increase in short term mortality in intensive care unit patients and increased long term mortality in patients with heart disease ${ }^{7,8}$. This is known as nonthyroidal illness syndrome (NTIS) or sick euthyroid syndrome. Abnormalities of thyroid function in NTIS have been classified as low T3 syndrome, low T3-low T4 syndrome, high T4 syndrome and other abnormalities ${ }^{7}$. The most common pattern is a decrease in T3 level with normal level of thyroxine (T4) and thyroid stimulating hormone $(\mathrm{TSH})^{9,10}$. This is known as low T3 syndrome. In more severe illness T3 and T4 level are reduced while TSH level does not show expected pituitary thyroid axis reactivity ${ }^{9}$. This is known as low T4 syndrome. Serum TSH in NTIS is typically normal or reduced. Some patients are found with a TSH level above normal and elevation of TSH above normal commonly occurs if patients recover ${ }^{10}$. Low T3 syndrome is common in critically ill patients, and it has been well demonstrated that low T3 syndrome was independently associated with greater mortality rate and worse functional outcomes across different populations of patients, including patients after acute cardiac events ${ }^{11}$, patients with respiratory failure ${ }^{12}$, intensive care unit patients ${ }^{13}$, and after surgery for brain tumor ${ }^{14}$. Similar results were also reported in stroke patients. For example, it has been shown that ischemic stroke patients with low T3 syndrome were at increased risk for poor functional outcome at followup that was scheduled from 2 to 4 weeks after ischemic stroke ${ }^{15}$. Another study found that 1 -year survival was significantly worse in stroke patients with low T3 syndrome ${ }^{16}$. Also, a study from India reported that lower total T3 concentrations were associated with poor neurological presentation and worse clinical outcome 7 days after acute stroke ${ }^{6}$. All the studies mentioned above investigated total T3 concentration. Some studies also reported low FT3 levels are related to poor prognosis in acute ischemic stroke patients ${ }^{17,18,19}$. Whereas an increase in TSH level has been described to be associated with better outcome in stroke patients in some studies ${ }^{16,17}$. So the probable correlation between alteration of thyroid hormone and severity of stroke and its outcome needs further investigation.

\section{Materials and Methods:}

It was a cross sectional Analytical study conducted in the Department of Neurology, Bangabandhu Sheikh Mujib Medical University (BSMMU), Dhaka. All adult acute ischemic stroke patient of both sex, meeting the inclusion and exclusion criteria were included in the study.

Total 60 (sixty) acute ischemic stroke patients within 14 days of onset of symptoms who admitted in the inpatient ward of Department of Neurology, BSMMU were selected and enrolled purposively for the study. Informed written consent was taken from each patient or from patient's attendant. Detailed history was taken from each patient and through physical examination was performed. Partial demographic profile including age, sex, residence, occupation, marital status, educational level, income status was recorded. Information regarding hypertension, smoking, diabetes, ischemic heart disease, valvular heart disease and other relevant history were recorded through a structured questionnaire. Stroke severity was assessed on the basis of National Institutes of Health Stroke Scale (NIHSS) on admission. Blood sample were collected for serum thyroid hormone (FT3, FT4, TSH) levels measurement within the first 2 weeks of the onset of stroke symptoms in the Department of Biochemistry at BSMMU. Serum thyroid hormone was measured by chemiluminescent microparticle immunoassay (Abbot Architect ci 8200, co-USA). All other relevant investigations (Plasma glucose level, Fasting lipid profile, Serum creatinine, ECG, Echocardiogram) were also done in BSMMU. On day 30 functional outcome was assessed by using the modified Rankin Scale (mRS). Total patients were divided into two groups according to functional outcome as poor outcome and good outcome. Poor outcome was defined as $\mathrm{mRS}>2$ or death and good outcome as $\mathrm{mRS} 0-2^{19}$. All the data were checked and edited after collection. Continuous variables were expressed as Mean \pm SD. Categorical variable was presented by frequency, percentage and graph. Qualitative data were analyzed by chi-square test. Quantitative data were analyzed by unpaired t-test. Pearson's correlation coefficient test was done to see the correlation between variables. Logistic regression analysis was used to evaluate association of other variables. $p$ value of $<0.05$ was considered statistically significant. Statistical 
analysis were done using SPSS (Statistical package for social sciences) windows version 22 software programme.

\section{Results:}

The mean age $( \pm S D)$ of the study population was $59.16( \pm 12.30)$ years with a range from 30 to 81 years. The mean age of the good outcome group (mRS 0-2) was a bit lower than that of poor outcome group (mRS>2). Regarding sex $56.7 \%$ patients were female and $43.3 \%$ male. Male and female ratio was 1: 1.3. (Table I). Study population by NIHSS, it was found $27(45 \%)$ patients with minor stroke, 31(51.7\%) patients with moderate stroke and $2(3.3 \%)$ patients with moderate to severe stroke (Table I). Thyroid hormone status in study population, it was found that serum FT3 level was decreased in 21(35\%) Patients but FT4 level was decreased in only $2(3.3 \%)$ patients and TSH level in $4(6.7 \%)$ patients (Table II).

The mean value of serum FT3 level level in poor outcome group were found lower than good functional outcome group which was statistically significant $(p<0.05)$ (Table III). Significant association $(p<0.001)$ of serum FT3 concentration with $\mathrm{mRS}$ after 1 month of stroke (Table $\mathrm{V}$ ) was found. Significant association $(p<0.005)$ was also found of admission NIHSS with mRS after 1 month of stroke. Moderate and moderate to stroke type of stroke are statistically significant with outcome (Table VI).

Correlation between serum FT3 level and outcome after 1 month (based on mRS score). Pearson's correlation coefficient test was done. Here we found negative correlation co-efficient $\left(r_{s}=-0.380\right)$ which was statistically significant $(p=0.001)$ (Fig. 1). Logistic regression analysis was done for prediction of acute ischemic stroke outcome within one month. It revealed that Age, hypertension, family history, NIHSS and serum FT3 level were found independent predictor for acute ischemic stroke outcome within one month.

Table I shows the demographic profile of the study population. The most frequent age group was 5160 years representing $33.3 \%$. Male and female ratio was 1: 1.3 . Most of the patients $29(48.3 \%$ ) were housewife.

Table-I

Distribution of the study population by demographic variables according to outcome (Based on mRS score) $(n=60)$

\begin{tabular}{|c|c|c|c|c|}
\hline Characteristics & $\begin{array}{c}\text { Good outcome } \\
\text { (mRS 0-2) } \\
\mathrm{n}(\%)\end{array}$ & $\begin{array}{c}\text { Poor outcome } \\
\text { (mRS>2) } \\
\mathrm{n}(\%)\end{array}$ & $\begin{array}{l}\text { Total } \\
\mathrm{n}(\%) \\
\end{array}$ & $P$ value \\
\hline \multicolumn{5}{|l|}{ Age in years } \\
\hline $30-40$ & $6(18.8)$ & $0(00)$ & $6(10)$ & $0.054^{\mathrm{ns}}$ \\
\hline $41-50$ & $4(12.5)$ & $6(21.4)$ & $10(16.7)$ & \\
\hline $51-60$ & $12(37.5)$ & $8(28.6)$ & $20(33.3)$ & \\
\hline $61-70$ & $8(25)$ & $10(35.7)$ & $18(30)$ & \\
\hline$>70$ & $2(6.2)$ & $4(13.3)$ & $6(10)$ & \\
\hline Mean $\pm S D$ & $56.31 \pm 12.52$ & $62.42 \pm 11.40$ & $59.16 \pm 12.30$ & \\
\hline Range & $30-75$ & $45-81$ & $30-81$ & \\
\hline \multicolumn{5}{|l|}{ Sex } \\
\hline Male & $12(37.5)$ & $14(50)$ & $26(43.3)$ & $0.330^{\text {ns }}$ \\
\hline Male female ratio & $1: 1.3$ & & & \\
\hline \multicolumn{5}{|l|}{ Monthly income } \\
\hline $5000-10000$ & $1(3.2)$ & $3(10.3)$ & $4(6.7)$ & $0.405^{\mathrm{ns}}$ \\
\hline $10000-20000$ & $8(25.8)$ & $8(27.6)$ & $16(26.6)$ & \\
\hline $20000-30000$ & $13(41.9)$ & $6(20.7)$ & $19(31.7)$ & \\
\hline $30000-40000$ & $5(16.1)$ & $6(20.7)$ & $11(18.3)$ & \\
\hline$>40000$ & $4(12.9)$ & $6(20.7)$ & $10(16.7)$ & \\
\hline
\end{tabular}


Table II

Distribution of the study population by NIHSS on admission $(n=60)$

\begin{tabular}{lcc}
\hline NIHSS & Number & Percentage \\
\hline $\begin{array}{l}\text { Normal/near normal (0-1) } \\
\text { examination }\end{array}$ & 0 & 00 \\
Minor stroke (1-4) & 27 & 45.0 \\
Moderate stroke (5-15) & 31 & 51.7 \\
Moderate to Severe & 2 & 3.3 \\
Stroke (15-20) & & \\
Severe stroke $(>20)$ & 0 & 00 \\
\hline
\end{tabular}

Table II shows distribution of study population by NIHSS. It was found 27(45\%) patients with minor stroke, $31(51.7 \%)$ patients with moderate stroke and $2(3.3 \%)$ patients with moderate to severe stroke.

Table-III

Thyroid hormone status on admission in study population $(n=60)$

\begin{tabular}{lcc}
\hline Serum thyroid hormone & Number & Percentage \\
\hline FT3 & & \\
$\quad$ Decreased & 21 & 35.0 \\
$\quad$ Normal & 39 & 65.0 \\
FT4 & & \\
$\quad$ Decreased & 2 & 3.3 \\
$\quad$ Normal & 58 & 96.7 \\
TSH & & \\
$\quad$ Decreased & 4 & 6.7 \\
$\quad$ Normal & 56 & 93.3 \\
\hline
\end{tabular}

Table III shows thyroid hormone status in study population. It was found that serum FT3 level was decreased in $21(35 \%)$ patients.

\section{Table-IV}

Distribution of mean serum thyroid hormones level in study population according to functional outcome group. $(n=60)$

\begin{tabular}{lccc}
\hline & $\begin{array}{c}\text { Good } \\
\text { functional } \\
\text { outcome } \\
\text { (mRS 0-2) }\end{array}$ & $\begin{array}{c}\text { Poor } \\
\text { functional } \\
\text { outcome } \\
\text { (mRS }>2)\end{array}$ & P value \\
\hline FT3pmol/L & $3.67 \pm 0.65$ & $2.77 \pm 0.99$ & $0.001^{\mathrm{s}}$ \\
FT4pmol/L & $13.52 \pm 1.11$ & $14.21 \pm 2.79$ & $0.200^{\text {ns }}$ \\
TSHmIU/L & $2.91 \pm 0.99$ & $2.38 \pm 1.01$ & $0.047^{\text {ns }}$ \\
\hline
\end{tabular}

$\mathrm{s}=$ significant, ns=not significant, Unpaired t-test was done to measure the level of significance.
Table IV shows The mean value of serum FT3 level in poor outcome group were found lower than good functional outcome group which was statistically significant $(p<0.05)$.

Table-V

Association of FT3 level and functional outcome of study population $(n=60)$

\begin{tabular}{lccc}
\hline FT3 level & $\begin{array}{c}\text { Good } \\
\text { functional } \\
\text { outcome } \\
(\mathrm{mRS} 0-2)\end{array}$ & $\begin{array}{c}\text { Poor } \\
\text { functional } \\
\text { outcome } \\
(\mathrm{mRS}>2)\end{array}$ & P value \\
& $\mathrm{n}(\%)$ & $\mathrm{n}(\%)$ & \\
\hline Decreased & $3(9.4)$ & $18(64.3)$ & $<0.001^{\mathrm{s}}$ \\
Normal & $29(90.6)$ & $10(35.7)$ & \\
\hline Total & $32(100)$ & $28(100)$ & \\
\hline
\end{tabular}

$\mathrm{S}=$ Significant, Chi-square test was done to measure the level of significance

Table $V$ shows significant association $(p<0.001)$ of serum FT3 concentration with mRS after 1 month of stroke.

Table-VI

Association of admission NIHSS level and functional outcome of study population $(n=60)$

\begin{tabular}{lccc}
\hline NIHSS & $\begin{array}{c}\text { Good } \\
\text { functional } \\
\text { outcome } \\
(\mathrm{mRS} 0-2) \\
\mathrm{n}(\%)\end{array}$ & $\begin{array}{c}\text { Poor } \\
\text { functional } \\
\text { outcome } \\
(\mathrm{mRS}>2) \\
\mathrm{n}(\%)\end{array}$ & P value \\
\hline Minor stroke & $22(68.8)$ & $5(17.9)$ & $0.001^{\mathrm{s}}$ \\
Moderate stroke & $10(31.2)$ & $21(75)$ & \\
$\begin{array}{l}\text { Moderate to severe } \\
\text { stroke }\end{array}$ & $0(00)$ & $2(7.1 \%)$ & \\
Severe & $0(00)$ & $0(00)$ & \\
\hline
\end{tabular}

$\mathrm{S}=$ Significant, Chi-square test was done to measure the level of significance

Table VI showed significant association $(p<0.005)$ of admission NIHSS with mRS after 1 month of stroke. Moderate and moderate to stroke type of stroke are statistically significant with outcome. 
Table VII

Logistic regression analysis for prediction of acute ischemic stroke outcome within one month (based on $m R S$ score)

\begin{tabular}{lcccccc}
\hline Variable & Beta & S.E & P value & OR & \multicolumn{2}{c}{$95 \% \mathrm{Cl}$} \\
\cline { 5 - 7 } & & & & & Lower & Upper \\
\hline Age & 1.179 & 0.592 & 0.007 & 3.250 & 1.018 & 10.379 \\
Male Sex & 0.511 & 0.526 & 0.331 & 0.331 & 0.600 & 1.669 \\
Smoking & 0.059 & 0.542 & 0.914 & 0.061 & 0.366 & 1.070 \\
DM & 0.251 & 0.519 & 0.629 & 1.286 & 0.464 & 1.559 \\
HTN & 1.017 & 0.669 & 0.001 & 8.167 & 0.093 & 3.174 \\
Dyslipidemia & 0.511 & 0.568 & 0.368 & 0.600 & 0.197 & 1.825 \\
Heart disease & 2.598 & 0.710 & 0.999 & 0.019 & 0.111 & 0.357 \\
Family History & 1.275 & 0.609 & 0.036 & 4.572 & 0.085 & 0.921 \\
NIHSS $(>4)$ & 3.258 & 0.705 & 0.001 & 6.00 & 6.532 & 20.498 \\
FT3 & 2.856 & 0.723 & 0.001 & 3.576 & 0.014 & 1.237 \\
FT4 & 0.426 & 1.772 & 0.999 & 0.112 & 0.012 & 0.231 \\
TSH & 0.223 & 1.037 & 0.830 & .800 & 0.105 & 2.204 \\
\hline
\end{tabular}

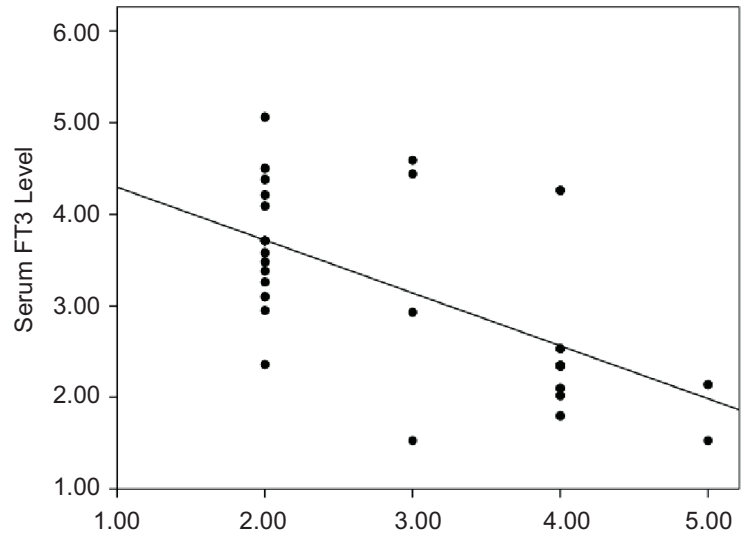

Fig.-1: Correlation between serum FT3 level and $m R S$ score

Figure 1 shows correlation between serum FT3 level and outcome after 1 month (based on mRS score). Pearson's correlation coefficient test was done. Here we found negative correlation coefficient $\left(r_{s}=-0.380\right)$ which was statistically significant $(p=0.001)$.

The table VII shows the result of logistic regression analysis for prediction of acute ischemic stroke outcome within one month. It revealed that Age, hypertension, family history, NIHSS and serum FT3 level were found independent predictor for acute ischemic stroke outcome within one month.

\section{Discussion:}

This current study was done with an aim to find out the association of serum thyroid hormone concentration with functional outcome of acute ischemic stroke patients. In this study some relevant risk factors that may affect the outcome and some demographic profile like age, sex, occupation and income status were also evaluated. This was a cross sectional analytical study done on the first ever ischemic stroke patients admitted in the department of neurology, BSMMU from April 2017 to April 2018. A total of 60 patients were assessed in this work. The mean ( \pm SD) age of the study population, was found to be $59.16 \pm 12.30$ years ranging from 30 to 81years, with a male/ female ratio of $1: 1.3$. The maximum number $(33.3 \%)$ of the patients were in the $51-60$ years age group. Most of the patients (31.6\%) per month family income were in between 20,000 to 30,000 taka followed by $30 \%$ patients per month family income were in between 10,000 to 20,000 taka. In a previous study Rahman et al. ${ }^{20}$ found that the mean $( \pm S D)$ age was $64.06 \pm 11.238$ years with a male/female ratio of 1.9:1. In another study, Saha et al. ${ }^{21}$ found that the mean ( \pm SD) age was $59.97 \pm$ 12.12 years with a male/female ratio of 1.6:1. Since, both of these studies were conducted on the Bangladeshi population, the results were nearly 
similar to one another. However, these demographic profiles are likely to vary when the study population is different. Zhang \& Meyer ${ }^{10}$ and Delpont et al. ${ }^{22}$ found that mean age of $68 \pm 12$ and $69.4 \pm 15.4$ years and a male/female ratio of 1.55:1 and 1.56:1 respectively in European population. These results showed that the patients are of older age and the frequency of male patients were higher than females in European population. In contrast, current study population shows the patients were of relatively younger age and frequencies of female slight higher than male. Higher average life expectancy in European people may explain the older age but explanation of differences in sex may be due to acute ischemic stroke patient admitted more in the female ward than male ward of BSMMU during this study period. Considering socioeconomic status most of the patients $(31.6 \%)$ per month family income were in between 20,000 to 30,000 taka followed by $30 \%$ patients per month family income were in between 10,000 to 20,000 taka.

The general objective of this study was to assess the association of serum thyroid hormones level with outcome in acute ischemic stroke patients. Among the thyroid hormones FT3 level was reduced in $21(35 \%)$ patients but $\mathrm{FT} 4$ and $\mathrm{TSH}$ reduced only in two and four patients respectively. The mean $( \pm$ SD) serum FT3 Level was 2.77 $( \pm 0.99) \mathrm{pmol} / \mathrm{Lin}$ poor outcome group and 3.67 $( \pm 0.65) \mathrm{pmol} / \mathrm{L}$ in good outcome group in the present study. Likewise serum FT3 level 2.19 $( \pm 0.45) \mathrm{pg} / \mathrm{mL}$ in poor outcome group and 2.45 $( \pm 0.57) \mathrm{pg} / \mathrm{mL}$ in good outcome group (Suda et al., 2016). ${ }^{17}$ In another study it was 2.39 (2.12-2.66)pg/ $\mathrm{mL}$ and 2.54(2.29-2.85)pg/mL respectively (Xu yan et al., 2015) ${ }^{23}$. This may be due to different method of measurement of serum thyroid hormone level. Patients with poor outcome had significant low serum FT3 level than patients with good outcome (2.77 $( \pm 0.99) \mathrm{pmol} / \mathrm{L}$ versus $3.67( \pm 0.65) \mathrm{pmol} / \mathrm{L})$. In current study, serum FT3 level on admission was highly significant $(p<0.001)$ with $\mathrm{mRS}$ score after 1 month of stroke. This study concluded that decrease serum FT3 level was associated with poor outcome (mRS score $>2$ ) of acute ischemic stroke patients. In one study (Delpont et al., 2016) ${ }^{22}$ showed that an increase in TSH level was associated with better outcome at discharge. Baek et al (2010) also showed favorable influence of subclinical hypothyroidism on the functional outcome in stroke patients. In the current study we found no such association.

In logistic regression analysis for serum FT3 level variable that the estimated odds ratio (OR) was 3.576, which means the patients with low serum FT3 level have odds to have poor outcome and this was significant at a $p$-value of 0.001 . It was observed that higher concentration on admission is more likely to have favorable outcome in acute ischemic stroke than low serum FT3 level.On one previous study (Xu yan et al., 2016) ${ }^{23}$ lower total T3concentrations was found to be independently associated with poor functional outcome $(\mathrm{OR}=0.10$ ; $95 \% \mathrm{Cl}=0.01-0.84, \mathrm{p}=0.035)$ and in another one (Suda et al., 2016), ${ }^{17}$ lower serum FT3 level was found to be an independent predictor of poor outcome $(\mathrm{OR}=9.92 ; 95 \% \mathrm{Cl}=4.82-21.33, \mathrm{p}=$ $<0.0001$ ) of ischemic stroke. All of these above mentioned previous studies coincide with the finding of current study. Overall, in all of the studies including the current one, it can be assumed that serum FT3 concentration on admission was associated with functional outcome of acute ischemic stroke.

\section{Conclusion:}

In conclusion, this study revealed that lower serum FT3 concentration in acute ischemic stroke is significantly associated with poor functional outcome. So, it might be considered as an important promising prognostic biomarker for assessing the severity, course and prognosis in early stage of the disease and therefore, active management in acute stage would be helpful in decreasing the risk of poor outcome.

\section{References:}

1. World Health Organization. World Fact Sheet, Geneva: WHO 2015.

2. Langhorne, R. Stroke disease. In: Colledge, N.R., Walker, B.R., Ralston, S.H., Penmen, I.D. 22th edn. Davidson's Principle and Practice of Medicine. London: Elsevier. 2014;425-30. 
3. Islam, M.N., Moniruzzaman, M., Khalil, M.I., Basri, R., Alam, M.K., Loo, K.W. (2013) 'Burden of stroke in Bangladesh', Int J Stroke 2013; 8 (3):211-13

4. Biller, J., Ruland, S ., Schneck, M.J. Ischemic Cerebrovascular Disease. In: Daroff, R.B., Jankovic, J., Mazziotta, J.C., Pomeroy, S.L.7th edn. Bradley'sneurology in clinical practice, Elsevier Health Sciences. 2015; 375-80.

5. Ropper, A.H., Samuels, M.A., Klein, J.P. Adams and Victor's principles of Neurology, 10 ${ }^{\text {th }}$ edn, New York: McGraw-Hill 2014; 420-25.

6. Pal, s.k., Santra, T., Agrawal,N., Adhikary, A., Bar, M., Ranjan, K \& Bhattacharjee, K. Clinical analysis on alteration of thyroid hormone in acute stroke patients and its effects on clinical outcome, European J of Biomedical and Pharmaceutical Sciences 2016;3(5):340-44.

7. Chopra, I.J. Clinical review 86; Euthyroid sick syndrome: is it a misnomer?' J Clin Endocrinol Metab 1997; 82:29-34.

8. Van den Berghe, G., Zegher, F., Bouillon R. Clinical review 95:Acute and prolonged critical illness as different neuroendocrineparadigms J Clin Endocrinol Metab,vol.83, pp.1827-34

9. De Groot, L.J. Dangerous dogmas in medicine: the nonthyroidalillness syndrome، , J Clin Endocrinol Metab 1999;8:51-64.

10. Jameson, J.L., Weetman, A.P. Disorders of the thyroid gland'. In : Longo, D.L., Fauci, A.S., Kasper, D.L., Hauser, S.L., Jameson, J.L., Loscalzo, J. 19thedn. Harrison's principles of internal medicine .New York : McGraw Hill 2015

11. Iervasi,G., Pingitore,A., Landi,P., Raciti,M., Ripoli,A., Scarlatini,M., LAbbate,A., Donato,L. Low T3 syndrome : a strong prognostic predictor of death in patients with heart disease', circulation, 2003;107(5), pp.704-13.

12. Sacco R.L., Kasner S.E., Broderick J.P., Caplan L.R., Culebras A., George M.G et al. An Updated Definition of Stroke for the $21^{\text {st }}$
Century: A Statement for Healthcare Professionals From the American Heart Association/American Stroke Association'. Stroke 2013; vol.44 pp.2064-89.

13. Plikat, K., Langgartner, J., Buettner, R., Bollheimer, L.C., Woenckaus, U.,Scholmerich , J., Wrede,C.E. Frequency and outcome of patients with nonthyroidal illness syndrome in a medical intensive care unit',Metabolism: Clinical and Experimental 2007; 6( 2): 239-44

14. Bunevicius, A., Kazlauskas, H., Raskauskiene, N., Mickuviene, N., Ndreu, R., Corsano, E.(2014) 'Role of N-Terminal ProB-Type Natriuretic Peptide, High-Sensitivity CReactive Protein, and Inteleukin-6 in Predicting a Poor Outcome after a Stroke'. Neuroimmunomodulation 2014;12-18

15. Zhang, $Y$ and Meyer, M.A. Clinical analysis on alteration of thyroid hormones in the serum of patients with acute ischemic stroke,'Stroke Research and Treatment, 2010:1-5.

16. Alevizaki, M., Synetou, M., Xynos, K., Papa, T. \&Vemmos, K.N. Low triiodothyronine : a strong predictor of outcome in acute stroke patients', Eur J Clin Invest 2007; 651-57.

17. Suda, S., Muraga, K., Kanamaru, T., Okubo, S., Abe, A., Aoki, J., Suzuki, K., Sakamato, Y., Shimoyama, T., Nito, C \& Kimura, K. Low free triiodothyronine predicts poor functional outcome after acute ischemic stroke‘, Journal of the Neurological sciences 2016; 368:89-93.

18. O‘Keefe, L.M., Conway, S.E., Czap, A., Malchoff, C.D., Benashki, S., Fortunato, G., Staff, I \& McCullough, L.D. Thyroid hormones and functional outcomes after ischemic stroke‘, Thyroid Research 2015;1-7.

19. Ambrosius, W., Kazmierski, R., Gupta, V., Warot, A.W., Kocialkowska, D.A., Blazejewska, A., Ziembicka, K \&Nowinski, W.L. Low free triiodothyronine levels are related to poor prognosis in acute ischemic stroke', Experimental and Clinical Endocrinology andDiabetes 2011;119(3): 139-43. 
20. Rahman, A., Aydin, H.E., Komonchan,S., Saha,U.K., Quraishi, F.A., Hossain,S. Evaluation of modifiable risk factors for stroke in Bangladesh: A tertiary level hospital experience, International Journal of Clinical Medicine 2014; (4):140-45.

21. Saha1,R., Islam,M.M.S.U., Hossain,A.M., Kabir,M.R., Mamun,A..A., Saha,S.K., Mondal,S.K., Alam,M.J. Clinical Presentation and Risk Factors of Stroke-A Study of 100 HospitalizedStroke Patients in Bangladesh. Faridpur Medical CollegeJournal 2016; 11(1):23-25.
22. Delpont, B., Eboule, C.A., Durier, J., Petit, J.M., daumas, A., Legris, N., Daubail,B., Giroud, M., Bejot, Y. Associations between thyroid stimulating hormone levels and both severity and early outcome of patients with ischemic stroke, European neurology 2016;76:125-31

23. Xu, X., Li, W., Hu, X. Alteration of thyroid related hormones within normal ranges and functional outcomes in patients with acute ischemic stroke, International J of Endocrinology 2016:1-5. 